\title{
Management of Neural Tube Defect: A Single-Center Experience
}

Burçak Söylemez', [MD]

ORCID: 0000-0001-8626-6915

Zekeriya Bulut', [MD]

ORCID: 0000-0002-7663-4523

Fatih Koç', [MD]

ORCID: 0000-0002-7363-777X

Ünal Özüm', [MD]

ORCID: 0000-0003-2065-2033

Özen Karadağ' ${ }^{1}$ [MD]

ORCID: 0000-0002-2120-3881

\section{nee) ABSTRACT Cen}

Objective: Neural tube defects are a heterogeneous and complex group of congenital central nervous system anomalies involving that involve the failed closure of the vertebral column. The spinal cord is frequently affected, and neural tube defects substantially increase the risk of disability and death within the first year of life. Neural malformations are often associated with abnormalities in other organ systems. This study presents our clinical experiences regarding the development and comorbidities of infants with neural tube defect and compares them with the literature.

Materials and Methods: This retrospective study included 47 patients ( 24 females, 23 males) who underwent surgical treatment for neural tube defect in the neurosurgery department of Sivas Cumhuriyet University Faculty of Medicine Training and Research Hospital between 2000 and 2020.

Results: Of the 47 patients, 34 (72.34\%) had myelomeningocele and 13 (27.65\%) had meningocele. Lesion location was thoracolumbar in 38 patients $(80.85 \%)$, lumbar in $5(10.63 \%)$, lumbosacral in $3(6.38 \%)$, and cervical in 1 patient $(2.12 \%)$. Twenty-seven patients $(57.44 \%)$ underwent ventriculoperitoneal shunting due to hydrocephalus. Thirty patients (63.82\%) had Chiari malformation type II, 13 (27.65\%) had cranial anomalies, and 1 (2.12\%) had Down syndrome. In 9 patients, the conus medullaris terminated at or below the L3 vertebral body (19.14\%). Two patients (4.25\%) died.

Conclusion: Because of their multidimensional nature, neural tube defects have various effects on individuals, families, society, and the field of medicine. This study represents a small group of patients with neural tube defects. Cases should be included from other centers to compile more comprehensive data about patients with neural tube defects in Turkey.

Keywords: Chiari malformation type II, hydrocephalus, myelomeningocele, neural tube defect, prognosis
Department of Neurosurgery, Faculty of Medicine Sivas

Cumhuriyet University 58140, Sivas, Turkey.

E-mail: burci1986@gmail.com

https://doi.org/10.32552/2021.ActaMedica.500

Received: 31 August 2020, Accepted: 5 January 2021,

Published online: 5 February 2021

\section{INTRODUCTION}

Neural tube defect (NTD) is a congenital condition in which the vertebral column fails to close and frequently affects the spinal cord. NTD substantially increases the risk of disability and death within the firstyear of life [1-3]. Both genetic and environmental factors are involved in the development of NTD [4, 5]. Moreover, its incidence can vary according based on the development status of the country, race, and sex of the child as well as the socioeconomic and education levels of the family [2, 5-7]. Different studies have reported the incidence of NTD as 0.72 to 6.2 per 1000 live births [1, 2, 5, 7-9]. Middle- and low-income countries have a higher incidence of NTD [1].

Primary neurulation begins at weeks 3 and 4 of gestation. NTDs occur when the embryonic 
neural tube fails to close by week 5 or $6[2,10,11]$. NTDs are a heterogeneous and complex group of central nervous system (CNS) anomalies. The most common form of NTD is myelomeningocele (MMC) $[2,3,8,11]$. In addition, neural malformations are often associated with abnormalities in other organ systems [2, 3, 11-14]. NTD is accompanied by hydrocephalus in $90 \%$, Chiari malformation type II in $70 \%$, scoliosis in $>50 \%$, and kyphosis in about $20 \%$ of patients $[12,15]$.

This study presents our clinical experiences regarding the development and comorbidities of infants with NTD and compares them with the literature.

\section{MATERIALS and METHODS}

This retrospective study was performed after obtaining ethical approval from the noninterventional clinical research ethics committee of Sivas Cumhuriyet University (2020$03 / 24,18.03 .2020$ ). We retrospectively evaluated the medical records of 47 patients who underwent surgical treatment for NT in the neurosurgery department of Sivas Cumhuriyet University Faculty of Medicine Training and Research Hospital between 2000 and 2020. Of these, 24 patients $(51.06 \%)$ were female, and 23 (48.93\%) were male. Patients underwent surgical procedures between postnatal day 1 and day 10 , as they became eligible for anesthesia. Postoperatively, the patients were monitored for hydrocephalus by examination of head circumference and fontanel bulging. Patients also underwent postoperative follow-up cranial and spinal magnetic resonance imaging (MRI) or cranial computed tomography if performing MRI was not possible.

\section{RESULTS}

Among the total 47 patients included in the study, 34 (72.34\%) had MMC, and 13 (27.65\%) had meningocele. The lesions were thoracolumbar in 38 patients $(80.85 \%)$, lumbar in 5 (10.63\%), lumbosacral in $3(6.38 \%)$, and cervical in 1 patient (2.12\%).Twenty-seven patients (57.44\%) underwent ventriculoperitoneal (VP) shunting due to hydrocephalus. Seven patients (25.92\%) developed shunt infection within one year of the VP shunting procedure. Shunt surgery was performed within the first 10 days in 12 patients (44.44\%), between day 11 and 30 in 9 patients (33.33\%), and between day 31 and 365 in 6 patients (22.22\%). Thirty patients (63.82\%) had Chiari type II malformation, 13 (27.65\%) had cranial malformations (e.g., agenesis/dysgenesis of the corpus callosum, colpocephaly), and 1 (2.12\%) had Down syndrome. In 9 (19.14\%) patients, the termination level of the conus medullaris was at or below the L3 vertebra. Two (4.25\%) of the patients died, one at age 3 years and the other at age 4 years (Table 1 ).

\section{DISCUSSION}

NTD is a congenital abnormality that causes longterm disability and a significant burden on patients, their families, the health system, and society [16]. Half of all congenital anomalies cannot be linked to a specific cause. However, genetic factors

Table 1. Clinical and surgical characteristics of patients with neural tube defect

\begin{tabular}{|c|c|}
\hline & $\begin{array}{l}\text { Number of } \\
\text { patients (\%) } \\
\mathrm{n}=47\end{array}$ \\
\hline Male & $23(48.93)$ \\
\hline Female & $24(51.06)$ \\
\hline \multicolumn{2}{|l|}{ Primary diagnosis } \\
\hline Myelomeningocele & $34(72.34)$ \\
\hline Meningocele & $13(27.65)$ \\
\hline \multicolumn{2}{|l|}{ Functional lesion level } \\
\hline Thoracic & $1(2.12)$ \\
\hline Thoracolumbar & $38(80.85)$ \\
\hline Lumbar & $5(10.63)$ \\
\hline Lumbosacral & $3(6.38)$ \\
\hline \multicolumn{2}{|l|}{ Conus medullaris level } \\
\hline L1-L2 & $38(80.85)$ \\
\hline L3 or lower & $9(19.14)$ \\
\hline \multicolumn{2}{|l|}{ Associated CNS malformation } \\
\hline Hydrocephalus & $27(57.44)$ \\
\hline Chiari II & $30(63.82)$ \\
\hline Corpus callosum agenesis/dysgenesis & $13(27.65)$ \\
\hline VP shunt & $27(57.44)$ \\
\hline VP shunt infection & $7(25.92)$ \\
\hline \multicolumn{2}{|l|}{ Age at VP shunt (days) } \\
\hline $1-10$ & $12(44.44)$ \\
\hline $11-30$ & $9(33.33)$ \\
\hline $31-365$ & $6(22.22)$ \\
\hline Mortality & $2(4.25)$ \\
\hline
\end{tabular}

CNS: central nervous system; VP: ventriculoperitoneal. 
and environmental teratogens are significant contributors to the development of congenital anomalies $[5,4,16]$. The incidence varies between populations, with reported rates per 1000 live births of $0.89-0.93$ in European countries, $0.62-13.8$ in Arab countries, 0.53 in the United States, 0.19-6.6 in Southeast Asia, and 5.6-22.6 in Turkey [1, 2, 5]. Studies indicate that a daily supplement of $0.4 \mathrm{mg}$ folic acid during pregnancy can reduce the risk of NTD [1, 9, 16-18].

NTDs are a heterogeneous and complex group of CNS anomalies. Neural malformations and malformations in other organ systems often coexist in patients with NTDs $[2,3,11,13-15,19]$.

Although MMC is the most common form of NTD, others include lipomyelomeningocele, diastematomyelia, diplomyelia, myelocystocele, myeloschisis, and fatty filum $[2,3,8,22]$.

Among the 47 patients with NTD in our series, 27 (54.44\%) underwent VP shunting due to hydrocephalus. McDowell et al suggested that $85 \%$ of patients with MMC who undergo surgical closure of the defect developed hydrocephalus postoperatively, and $80-90 \%$ of these patients require the placement of a VP shunt for treatment [18]. In their study, Gaitanis et al demonstrated that the prevalence of hydrocephalus was related to lesion level, with hydrocephalus occurring in more than $90 \%$ of patients with lumbar lesions [11]. In a study by North et al., hydrocephalus was observed in $91-92 \%$ of patients with MMC, whereas shunt placement was performed in $76-84 \%$ [13].

Chiari type II malformation is frequently associated with NTDs. We detected Chiari type II malformation in 30 (63.82\%) of our patients. Turan et al [2] reported this rate to be $65 \%$. Çelik et al determined this rate to be $71.4 \%$ and showed that $71 \%$ of patients with hydrocephalus with VP shunt were diagnosed with Chiari type II malformation [20, 21]. In their study, Gaitanis et al reported that Chiari type II malformation was present in one-third of patients with MMC and caused severe morbidity and mortality. Chiari type II malformation is often detected in patients with a low pontomesencephalic junction [11]. In a study by Mitchell et al, although $75 \%$ of patients with MMC had radiological findings of Chiari type II malformation, only one-third of the patients were symptomatic [19]. According to the findings of Copp et al, $30 \%$ of patients are symptomatic. Chiari type II malformation is characterized by apnea, difficulty swallowing, and stridor in neonates, as well as headache, quadriparesis, scoliosis, and impaired balance/coordination in older children [3].

MMC is a complex CNS malformation that is frequently associated with other neural and extraneural anomalies. Malformation and hydrocephalus are exhibited in most Chiari type II patients. It is also associated with other anomalies of the CNS, including brainstem defects, dysgenesis of the corpus callosum, large massa intermedia, polymicrogyria, and low-lying tentorium. There are also anomalies observed in the cranial vault, vertebra, and ribs [14]. In our study, 13 (27.65\%) patients had agenesis or dysgenesis of the corpus callosum. The level of conus medullaris termination was the L3 vertebra or lower in 9 patients (19.14\%). Hannah et al reported various corpus callosum abnormalities in nearly all MMC patients in their study [22].

We observed a mortality rate of $4.25 \%$ in our study. One patient died at age 3 years, and the other at age 4 years. In a study of 40-year mortality among patients who underwent surgery for MMC in the United Kingdom between 1960 and 1970, the mortality rate was found to be associated with lesion level, with a $17 \%$ survival rate among patients with lesions above T11 and a $61 \%$ survival rate among those with lesions below L3 [23]. In patients with $\mathrm{MMC}$, the mortality rate was $1 \%$ per year between the ages of 5 and 30 years, with a higher rate observed in patients with higher-level lesions [3].

\section{CONCLUSION}

Because of their multidimensional nature, NTDs have various impacts on individuals, families, society, and the field of medicine. This study represents a small group of patients with NTDs. To compile more comprehensive data about NTD patients in Turkey, cases from other centers should be included.

\section{CONFLICTS of INTEREST}

The authors declare that there is no conflict of interest. 
[1] Gandy K, Castillo H, Rocque BG, et al. Neurosurgical training and global health education: systematic review of challenges and benefits of in-country programs in the care of neural tube defects. Neurosurg Focus 2020; 48: E14.

[2] Turhan AH, Isik S. Neural tube defects: A retrospective study of 69 cases. Asian J Neurosurg 2019; 14: 506-9.

[3] Copp AJ, Adzick NS, Chitty LS, et al. Spina bifida. Nat Rev Dis Primers 2015; 1: 15007.

[4] Greene ND, Copp AJ. Neural tube defects. Annu Rev Neurosci 2014; 37: 221-42.

[5] Zahed Pasha $Y$, Vahedi A, Zamani $M$, et al. Prevalence of Birth Defects in Iran: A Systematic Review and MetaAnalysis. Arch Iran Med 2017; 20: 376-85.

[6] Davis MC, Hopson BD, Blount JP, et al. Predictors of permanent disability among adults with spinal dysraphism. J Neurosurg Spine 2017; 27: 169-77.

[7] Canfield MA, Mai CT, Wang Y, et al. The association between race/ethnicity and major birth defects in the United States, 1999-2007. Am J Public Health 2014; 104: e14-23.

[8] Brei T, Houtrow A. Spina Bifida. J Pediatr Rehabil Med. 2017; 10: 165-166.

[9] Ulsenheimer MM, Antoniuk SA, Santos $L H$, et al. Myelomeningocele: A Brazilian University Hospital experience. Arq Neuropsiquiatr. 2004; 62: 963-8.

[10] Farmer DL, Thom EA, Brock JW 3rd, et al. The management of myelomeningocele study: Full cohort 30-month pediatric outcomes. Am J Obstet Gynecol 2018; 218: 256. e1-13.

[11] Gaitanis J, Tarui T. Nervous system malformations. Continuum 2018; 24: 72-95.

[12] Ryabykh SO, Pavlova OM, Savin DM, et al. Surgical Management of Myelomeningocele-Related Spinal Deformities. World Neurosurg 2018; 112: e431-41.
[13] North T, Cheong A, Steinbok P, et al. Trends in incidence and long-term outcomes of myelomeningocele in British Columbia. Childs Nerv Syst 2018; 34 :717-24.

[14] Nejat F, Kamali S, El Khashab M. Interfrontal encephalocele: a rare feature of forehead in hydrocephalic myelomeningocele patients. Clinical feature, probable mechanisms, and management. Childs Nerv Syst 2013; 29: 1349-52.

[15] McDowell MM, Lee PS, Foster KA, Greene S. The use of external ventricular drainage to reduce the frequency of wound complications in myelomeningocele closure. Pediatr Neurosurg 2018; 53: 100-7.

[16] World Health Organization, Congenital anomalies, 2016

[17] Copp AJ, Stanier P, Greene ND. Neural tube defects: Recent advances, unsolved questions, and controversies. Lancet Neurol 2013; 12: 799-810.

[18] Manning SM, Jennings R, Madsen JR. Pathophysiology, prevention, and potential treatment of neural tube defects. Ment Retard Dev Disabil Res Rev 2000; 6: 6-14.

[19] Mitchell LE, Adzick NS, Melchionne J, et al. Spina bifida. Lancet 2004; 364: 1885-95.

[20] Hannay HJ, Dennis M, Kramer L, et al. Partial agenesis of the corpus callosum in spina bifida meningomyelocele and potential compensatory mechanisms. J Clin Exp Neuropsychol 2009; 31: 180-94.

[21] Çelik HT, Meliboyev M, Nizamov İ, et al. Meningomyelocele and Arnold-Chiari malformation: Evaluation of 45 cases. Cocuk Sagligi ve Hastaliklari Dergisi 2010; 53: 10-6.

[22] McLone DG, Dias MS. The Chiari II malformation: Cause and impact. Childs Nerv Syst 2003; 19: 540-50.

[23] Oakeshott P, Hunt GM, Poulton A, et al. Open spina bifida: birth findings predict long-term outcome. Arch Dis Child 2012; 97: 474-6. 